\title{
Hyperinflammatory syndrome in children during the coronavirus disease 2019 pandemic in sub-Himalayan region
}

\section{To the editor,}

Hyperinflammatory syndromes are life-threatening disorders caused by overwhelming host immune responses often resulting from defects in negative feedback mechanisms. These include Kawasaki disease $(\mathrm{KD})$ and other serious pediatric inflammatory conditions, such as toxic shock syndrome (TSS) and macrophage activation syndrome (MAS). During the coronavirus disease 2019 (COVID-19) pandemic, a national alert was issued in the United Kingdom and North America in mid-April 2020, as they reported a cluster of children with a multisystem inflammatory condition with multiorgan involvement who required intensive unit care. ${ }^{1,2)}$ They presented with some features similar to KD, TSS, and MAS, with laboratory profiles revealing marked hyperinflammation. The World Health Organisation is calling it multisystem inflammatory syndrome. ${ }^{3)}$ However, the association between hyperinflammatory syndrome in children and COVID-19 is still not known. We are describing a case series of 10 patients with hyperinflammatory syndrome, highlighting clinical presentations, laboratory profiles, management, and outcome during this COVID-19 pandemic, to raise awareness among pediatricians.

This retrospective study was conducted in a tertiary care centre in North India from April through May 2020. The Institutional ethical committee approved the study. Patients of age between 1 month to $<19$ years with clinical features of persistent fever, inflammation, hypotension, and multiple organ failure, who were admitted in pediatric intensive care unit were included. We collected demographic data, past medical history, physical examination findings, chest x-ray, echocardiography (if done), and laboratory findings, including complete blood count with differential count, erythrocyte sedimentation rate (ESR), C-reactive protein (CRP), coagulation profile, ferritin, liver enzymes, lactate dehydrogenase, triglyceride, and D-dimer, performed at presentation and throughout the hospital stay. All patients had reverse-transcriptase polymerase chain reaction (RT-PCR) tests for COVID 19. Ten patients with features of hyperinflammation and multiorgan failure were admitted during the study period, whereas only 2 such patients were reported in last 6 months before COVID-19 pandemic in our centre. All these patients were of Indian origin. The median age was 13.5 years (9-17 years). Seven out of 10 patients $(70 \%)$ were male. These patients were critically sick with muco cutaneous manifestations, such as nonpurulent conjunctivitis, cracked lips, edema of hands or feet, and skin rash.

All of these patients were partially fulfilling the diagnostic criteria for KD by 2017 American Heart Association guidelines. They had hypotension at presentation, and their clinical features were consistent with $\mathrm{KD}$ shock syndrome. ${ }^{4)}$ We also considered MAS, which is a potentially life-threatening complication of $\mathrm{KD}$. We suspected MAS in 9 out of 10 patients (90\%) on the basis of clinical criteria. ${ }^{5)}$ In clinical profile, all patients presented with multiorgan failure with shock (Table 1). Two of our patients presented with decreased limb movement with absent deep tendon reflexes and axonal neuropathy on a nerve conduction study. Only 2 out of 10 patients (20\%) had gastrointestinal manifestations in the form of loose stools and vomiting. Blood test results showed raised inflammatory markers; raised CRP in 10 (100\%), raised ESR in 9 (90\%), hyperferritinemia in 9 (90\%), and raised D-dimer in 2 patients (20\%) (Table 1). All of 10 patients (100\%) had thrombocytopenia, and 5 patients (50\%) had lymphopenia. Coagulopathy was found in 7 patients (70\%). Chest x-ray was done in 9 patients, and was abnormal in 5 (50\%); bilateral infiltrates in 4 and pleural effusion in 1. Echocardiography showed aortic valve regurgitation in 1 patient (10\%). Reverse transcription-polymerase chain reaction (RTPCR) test for COVID-19 was done in all patients, and turned out to be negative. All of the patients required some levels of respiratory support, and $8(80 \%)$ required mechanical ventilation. All patients were treated with broad-spectrum antibiotics.

As all of the patients presented with shock, they were managed with inotropes/vasopressors. Six patients (60\%) received intravenous methylprednisolone, and 3 (30\%) received intravenous immunoglobulin (IVIG) along with corticosteroids. Seven patients (70\%) died, and 3 (30\%) were discharged.

$\mathrm{KD}$ is a pediatric disease showing acute systemic vasculitis, and is a major cause of acquired heart disease in children; approximately $25 \%$ of KD patients may develop chronic coronary artery lesions, if not treated early in the course of the disease. ${ }^{6}$ The clinical manifestations of $\mathrm{KD}$ are various, and patients may not completely fulfil the diagnostic criteria of $\mathrm{KD}$, called "incomplete or atypical" KD.7) Despite uncommon, KD patients may also present with hypotension; a severe form of $\mathrm{KD}$ known as $\mathrm{KD}$ shock syndrome (KDSS), which is associated with markedly raised inflammatory markers and considerable risk of cardiac involvement. These patients are pretty resistant to IVIG therapy, so often require additional anti-inflammatory treatments. ${ }^{4)}$ The 
Table 1. Clinical and laboratory profiles of children with hyperinflammatory syndrome

\begin{tabular}{|c|c|c|c|c|c|c|c|c|c|c|}
\hline Characteristic & Case 1 & Case 2 & Case 3 & Case 4 & Case 5 & Case 6 & Case 7 & Case 8 & Case 9 & Case 10 \\
\hline Mucocutaneous manifestations & + & - & + & - & + & + & + & - & - & + \\
\hline MODS & + & + & + & + & + & + & + & + & + & + \\
\hline Pneumonia & + & + & + & - & - & + & + & + & + & + \\
\hline Cardiogenic/septic shock & $+/-$ & $-/+$ & $-/+$ & $-/+$ & $-/+$ & $-/+$ & $-/+$ & $-1+$ & $-/+$ & $-/+$ \\
\hline Corticosteroids & + & - & - & + & + & - & + & - & - & + \\
\hline IVIG single dose ( $2 \mathrm{~g} / \mathrm{kg}$ ) & - & - & - & - & + & + & + & - & - & - \\
\hline Vasoactive drugs & Yes & Yes & Yes & Yes & No & No & Yes & Yes & Yes & No \\
\hline Mechanical ventilation & - & + & + & + & + & + & + & + & - & + \\
\hline Leukocyte (×10\%/L) & 7.70 & 2.50 & 13.30 & 15.20 & 4.30 & 8.00 & 4.490 & 8.00 & 15.70 & 7.40 \\
\hline Lymphocytes (×109/L) & 0.77 & 0.72 & 1.30 & 3.80 & 0.60 & 1.76 & 2.20 & 1.76 & 0.78 & 1.99 \\
\hline Platelets (×109 /L) & 38 & 69 & 14 & 130 & 30 & 11 & 59 & 11 & 43 & 120 \\
\hline CRP (mg/L) & $>12,<24$ & $>12,<24$ & $>12,<24$ & $>12,<24$ & $>24,<48$ & $>6,<12$ & $>24,<48$ & $>12,<24$ & $>12,<24$ & $>6,<12$ \\
\hline $\operatorname{ESR}(\mathrm{mm} / \mathrm{hr})$ & 80 & 35 & 60 & 35 & 98 & 35 & 35 & 40 & 25 & 35 \\
\hline Ferritin (ng/mL) & 902 & 1,100 & $>1,500$ & 1,370 & $>1,500$ & $>2,000$ & $>2,000$ & $>2,000$ & 1,440 & 120 \\
\hline Triglycerides (mg/dL) & 335 & 280 & 320 & 188 & 200 & 206 & ND & ND & 368 & ND \\
\hline PT & 17.3 & 14 & 12.3 & 18.2 & 11.9 & 25 & 16.6 & 16 & 15 & 13.3 \\
\hline aPTT & 36.5 & 32 & 30 & 33.5 & 33.5 & 42 & 40 & 38 & 30.2 & 29.2 \\
\hline INR & 1.35 & 1.08 & 1.2 & 0.88 & 1.88 & 1.2 & 1.46 & 1.6 & 1.4 & 1.05 \\
\hline $\mathrm{D}$-dimer ( $\mu \mathrm{g} / \mathrm{mL})$ & $>0.5,<1$ & $<0.5$ & $<0.5$ & $<0.5$ & $>2,<4$ & $<0.5$ & $<0.5$ & $<0.5$ & $<0.5$ & $<0.5$ \\
\hline Outcome & Survived & Died & Died & Died & Died & Died & Survived & Died & Survived & Died \\
\hline
\end{tabular}

MODS, multiple organ dysfunction syndrome; IVIG, intravenous immunoglobulin, CRP, C-reactive protein; ESR, erythrocyte sedimentation rate; ND, not done; PT, prothrombin time; aPTT, activated partial thromboplastin time; INR, international normalized ratio.

first-line treatment of KD involves the use of high-dose IVIG and aspirin. In our study, we found male predominance with a higher age distribution as compared to typical KD. MAS could be suspected in some of our patients; hyperferritinemia in 9 (90\%), hypertriglyceridemia in 8 (80\%), thrombocytopenia in $6(60 \%)$, and elevated transaminases in $8(80 \%)$. So we treated our patients with methylprednisolone, which is used as the firstline therapy in children with MAS. Recently published case series have shown that corticosteroids are useful adjunctive therapy to IVIG in patients with multisystem inflammatory syndrome in children. ${ }^{8)}$ Only 3 of our patients could survive, who received both anti-inflammatory and immunomodulatory therapy, and the mortality rate was very high (70\%). Similarly to our study, Verdoni et al. ${ }^{9)}$ found that older children were affected by a more severe form of $\mathrm{KD}$ with significant cardiac involvement, MAS or KDSS during the severe acute respiratory syndrome coronavirus-2 (SARS-CoV-2) epidemic, as compared to the pre-epidemic era. ${ }^{9)}$ Other systems involved were the respiratory, gastrointestinal and central nervous system, and lymphopenia and thrombocytopenia were present. They also noted more resistance to IVIG and the need for adjunctive corticosteroid therapy. ${ }^{9)}$ The limitation of our study is that we could not confirm any correlation of these patients with SARS-CoV-2 infection, as RT-PCR tests done on patients turned out to be negative, and we had no access to SARS-CoV-2 antibody test at our institution during the study period. We conclude that it is important to suspect hyperinflammatory syndrome in children with persistent fever, hypotension, and multiple organ failure during this COVID-19 pandemic. These patients can deteriorate very rapidly, if adequate treatment is not given early. Hence, early recognition and prompt treatment are essential for better outcomes of such patients with hyperinflammatory syndrome.

\section{Key message}

Question: Is there an increase in patients with hyperinflammatory syndrome during the coronavirus disease 2019 pandemic?

Finding: We found 10 patients with hyperinflammatory syndrome with poor outcome during a period of 2 months in a single tertiary care centre.

Meaning: Pediatricians who come across patients with muco cutaneous manifestations and multiorgan involvement should consider hyperinflammatory syndrome. Early recognition and prompt treatment of such patients may result in promising outcome.

\section{Conflicts of interest}

No potential conflict of interest relevant to this article was reported.

Seema Sharma, $\mathrm{MD}^{1}$, Shikha Verma, $\mathrm{MD}^{1}$, Isha Bhatia, $\mathrm{MBBS}^{1}$, Ravinder Singh, $\mathrm{MD}^{2}$, Mohit Bajaj, $\mathrm{MD}^{1}$, Milap Sharma, $\mathrm{MD}^{1}$

${ }^{1}$ Department of Pediatrics, Dr Rajendra Prasad Government Medical College, Kangra at Tanda, Himachal Pradesh, India ${ }^{2}$ Department of Dermatology, Dr Rajendra Prasad Government Medical College, Kangra at Tanda, Himachal Pradesh, India 
Corresponding author: Shikha Verma, MD

Department of Pediatrics, Dr Rajendra Prasad Government Medical College, Kangra at Tanda, Himachal Pradesh 176001 India

凶Email:shikhav784@gmail.com

https://orcid.org/0000-0002-8331-6283

\section{References}

1. Riphagen S, Gomez X, Gonzalez-Martinez C, Wilkinson N, Theocharis P. Hyperinflammatory shock in children during COVID-19 pandemic. Lancet 2020;395:1607-8.

2. Centers for Disease Control and Prevention. Emergency preparedness and response: Health alert network [Internet]. Atlanta (GA): Centers for Disease Control and Prevention; [cited 2020 May 22]. Available from: https://emergency.cdc.gov/han/2020/han00432.asp.

3. World Health Organization. Multisystem inflammatory syndrome in children and adolescents with COVID-19: scientific brief, 15 May 2020 [Internet]. Geneva (Switzerland): World Health Organization; [cited 2020 May 22]. Available from: https://apps.who.int/iris/handle/10665/ 332095.

4. Kanegaye JT, Wilder MS, Molkara D, Frazer JR, Pancheri J, Tremoulet $\mathrm{AH}$ et al. Recognition of a Kawasaki disease shock syndrome. Pediatrics 2009;123:e783-9.

5. Wu EY, Bryan AR, Rabinovich CE. Juvenile idiopathic arthritis. In: Kliegman RM, Stanton BF, St. Geme JW III, Schor NF, Behrman RE, editors. Nelson textbook of pediatrics. 20th ed. Philadelphia (PA); Elsevier; 2016:1160-70.

6. Kawasaki T, Kosaki F, Okawa S, Shigematsu I, Yanagawa H. A new infantile acute febrile mucocutaneous lymph node syndrome (MLNS) prevailing in Japan. Pediatrics 1974;54:271-6.

7. Burns JC, Glodé MP. Kawasaki syndrome. Lancet 2004;364:533-44.

8. Ouldali N, Toubiana J, Antona D, Javouhey E, Madhi F, Lorrot M, et al Association of intravenous immunoglobulins plus methylprednisolone vs immunoglobulins alone with course of fever in multisystem inflammatory syndrome in children. JAMA 2021;325:855-64.

9. Verdoni L, Mazza A, Gervasoni A, Martelli L, Ruggeri M, Ciuffreda M, et al. An outbreak of severe Kawasaki-like disease at the Italian epicentre of the SARS-CoV-2 epidemic: an observational cohort study. Lancet 2020;395:1771-8.

How to cite this article: Sharma S, Verma S, Bhatia I, Singh R, Bajaj M, Sharma M. Hyperinflammatory syndrome in children during the coronavirus disease 2019 pandemic in subHimalayan region. Clin Exp Pediatr 2021;64:370-2. https://doi. org/10.3345/cep.2020.02040 